\title{
Criminal punishment: humanism and security as vectors of development
}

\author{
Inna A. Podroykina, ${ }^{1, *}$, Vladimir K. Duyunov ${ }^{2}$, Ruslan V. Zakomoldin ${ }^{2}$ \\ ${ }^{1}$ Department of Criminal Law Disciplines, Rostov branch of the Russian Customs Academy, Rostov-on-Don, Russia \\ ${ }^{2}$ Department of Criminal Law and Procedure, Institute of Law, Togliatti State University, Togliatti, Russia
}

\begin{abstract}
The paper analyzes the changes in the criminal legislation that have passed since its adoption with an emphasis on those that were justified by the idea of humanization. The attention is drawn to the fact that, despite the fact that the criminal policy liberalization has been actively discussed in different years, in modern Russia criminalization processes dominate decriminalization processes, and the number of articles in the Special Part of the Criminal Code has increased by 1.5 times. Against this background, the authors emphasize that judicial practice has gone away from the use of punishment as the only possible and effective means of responding to infringing behavior. In general, while advocating the economy of criminal repression, as well as the wider use of other measures of the criminal law against the perpetrators of crimes, the authors nevertheless express concern that the law enforcement officer is overly humanistic towards the perpetrators of serious and especially serious crimes, widely using suspended sentences, as well as imposing a sentence that corresponds to a milder category of crimes. In conclusion, the opinion is expressed that the modern legislator needs to focus his efforts on creating a full-fledged system of criminal legal measures with a clear understanding that each of them individually, and the whole system as a whole, should effectively protect the interests of the individual, society and the state.
\end{abstract}

\section{Introduction}

Paragraph 43 of the National Security Strategy of the Russian Federation among the main threats to state and public security, includes, among others, the following: "criminal attacks against the person, property, state power, public and economic security" [1]. Paragraph 44 of the above Strategy states that "the main areas of state and public security are strengthening the role of the state as a guarantor of personal security and property rights, improving the legal regulation of crime prevention (including in the information sphere), corruption, terrorism and extremism, the spread of drugs and the fight against such phenomena, developing of interaction between state security and law enforcement agencies and civil society, increasing citizens' confidence in the law enforcement and judicial systems of the Russian Federation..." [1]. In turn, the Criminal Code, acting as a guarantor of those rights and freedoms defined at the level of the Basic Law of our state, ensuring the security of the person, society and the state (i.e. national security), established prohibitions on offending behavior and a fairly wide range of tools that have a punitive, educational and preventive effect on the behavior of offenders and other (unstable) persons.

The appeal to these documents, as it seems, should indicate that Russia created an effective mechanism through criminal legislation to ensure the national security against criminal attacks. Indeed, among the tasks of the criminal law the Art. 2 of the Criminal Code defined the protection of the most significant values the rights and freedoms of a person and a citizen, property, public order and public safety, etc. Art. 3-7 of the Criminal Code establishes guiding ideas on which all criminal legislation is based, and on which not only the law enforcement officer, but also the legislator filling the Criminal Code with new standards should be based in order to ensure the national security. The violation of the established prohibitions implies a reaction of the state in the form of a criminal punishment, which is the most stringent among the measures of legal responsibility, as well as other measures of criminal legal influence.

Every year, the criminal law is subject to certain adjustments, both in terms of the definition of the criminal and in terms of options for criminal legal response to offending behavior, which, should also logically be evaluated positively, since changing social relations should inevitably entail a change in the legislative framework. "Law, acting as the most important social regulator, provides scope for progressive undertakings and puts a barrier to everything that prevents this, therefore, the criminal law must be constantly modernized, improved taking into account the time requirements" [2, p. 13].

However, unfortunately, a more detailed analysis of the criminal law in the modern version, as well as judicial practice, challenges the earlier conclusion. At

Corresponding author: 919820@mail.ru 
least, it can be heavily qualified that the existing criminal law is effective in ensuring security. On the one hand, this is due to the fact that "the legislator seeks to respond in a timely and sufficiently harsh manner to new manifestations of criminal activity, to reduce the number of persons serving sentences in penal institutions, and to find forms of response to a crime other than punishment. On the other hand, it is obvious that a large part of the decisions taken is contradictory and inconsistent, does not correspond to the established criminal law doctrine, is not systematic, often contradicts the purposes and principles of the modern criminal law" [2, p. 13]. It is no coincidence that most of the changes made to the Criminal Code are critically evaluated in the theory of the criminal law [3, p. 46] [4, p. 85]. Against this background, judicial practice is not characterized by uniformity either in terms of the definition of crimes, or in terms of issues related to the determination of the type and amount of punishment, the use of other forms of criminal legal influence on the offender.

As a result, it can be stated that today the value orientations, on which it is necessary to rely both in lawmaking and in law enforcement, have been lost. Not always agreed and mutually conditioned changes in the law have led to the fact that the legislator and the enforcer, in fact, choose different paths, often "forgetting" about the principles that are laid down in the criminal legislation. For example, most of the newly introduced articles have not become subject to judicial practice and, are either not applied at all, or sentences on them are of a single nature. There are also opposite trends in punitive treatment. In particular, along with the humanization of the criminal law, the legislator, however, significantly increased the limits of punishment for a number of crimes, including terrorist ones, crimes against the sexual inviolability of minors related to trafficking in narcotic drugs and psychotropic substances and some others. However, the trends in judicial practice indicate that it is more focused on the criminal legal impact with minimal restrictions for the offender, including in cases of serious and especially serious crimes, which cannot be recognized as permissible and consistent with the principles of humanism and justice.

Therefore, today the solution to the problem of determining the optimal balance between the means of criminal legal response to criminal conduct used in practice and the fundamental tasks, goals laid down in the criminal law is considered relevant.

\section{Materials and methods}

The study is based on the method of systemic analysis along with formal-legal, comparative-legal, statistical and specifically sociological analyses.

\section{Results and Discussion}

As of May 4, 2021, 264 regulatory acts amending the Criminal Code were adopted. The intensity of the adopted laws supplementing the Criminal Code of the
Russian Federation over the course of almost twenty-five years has constantly changed. The first changes to it were made in 1998. At first, the legislator acted quite carefully. Between 1998 and 2009, adjustments were targeted and the number of laws enacted per year was relatively small - between 0 and 10 . Although it is worth noting that some of the laws adopted at that time affected dozens of articles and a number of criminal law institutions. For example, the Federal Law No. 162-FZ of 08.12.2003 [5] made 257 changes to the Criminal Code of the Russian Federation. Between 2010 and 2021 , the number of such laws is gradually increasing. The peak years were 2010 and 2013, when 22 laws were adopted, as well as 2014 - 23 laws. Some authors draw attention to the fact that "the scale and speed of amendments to the Criminal Code of the Russian Federation is much greater than in other countries, for example, than in the People's Republic of China" [6, p. 113].

During its existence, the General Part of the Criminal Code was replenished with 12 new articles, two were excluded. The changes did not affect only 42 articles of the General Part, which amounted to $36.8 \%$. In other words, most of the articles of the General Part of the Criminal Code have undergone editorial changes, and a number of them have been corrected repeatedly (for example, article 37, article 50 of the Criminal Code of the Russian Federation). A Special Part of the Criminal Code was replenished with 122 new articles, 11 were excluded. Only one chapter of the Special Part - chapter 33 "Crimes against Military Service" remained unchanged in the number of articles. Compared to the original version, today the number of articles in the Special Part of the Criminal Code has increased by $43.5 \%$, i.e. almost 1.5 times. In total, there are 366 articles in the Special Part of the Criminal Code. The largest changes in terms of criminalization were made to chapter 22 of the Criminal Code of the Russian Federation, now the number of articles in this chapter is 58 , i.e. an increase of 34 articles - by $81 \%$, almost doubled. Of the articles of the original edition of the Criminal Code, only one remained unchanged, according to our estimates this is 7 articles (art. 284, 339, 356, 335, 345, 358, 336, 353 of the Criminal Code of the Russian Federation). The adjustments dealt with a variety of aspects: clarifying the content of the main compositions, qualifying features, supplementing the articles with new notes in a new version, amending sanctions. Based on the above data, it is clear that criminalization processes prevail over decriminalization processes in the modern criminal legislation. According to some researchers, such dominance makes a 9:1 ratio [7, p. 44].

In this regard K.A. Volkov writes: "Considering the modern priority areas of Russian criminal policy it can be noted that in the field of criminal law policy such include the increased responsibility for terrorism and extremism, corruption, illegal trafficking of narcotic drugs and psychotropic substances, attacks against minors; humanization of criminal responsibility and punishment; decriminalization of economic offences" [8, p. 34]. So, it can be said that the changes that were made to the criminal law were not due to any single motive, 
and they were not unidirectional. They were based on various reasons - economic (for example, expanding the scope of chapter 22 of the Criminal Code of the Russian Federation), pragmatic ("unloading" the penal system), political (strengthening responsibility for crimes of an extremist nature, supplementing the Criminal Code with articles 361 and others), explained by humanization (expanding the variability of punishability, excluding the lower limits of penalties in a number of sanctions, etc.) and others. However, with regard to the topic of research, we will focus only on those processes that were due to the desire to humanize the criminal law (at least this was the official position).

The specialists in the field of criminal law and the Supreme Court emphasized the need to humanize the criminal law and the practice of its application in the late 1990s and early 2000s. In this regard, as well as based on statistics on the deprivation of liberty, in 2002, the President of Russia V.V. Putin in his annual message to the Federal Assembly of the Russian Federation officially outlined the course towards reducing the use of this punishment, improving the system of execution of criminal penalties, as well as the liberalizing the criminal policy in general. At that time, such liberalization was indeed necessary, at least in terms of the punishability of crimes.

This was due to the fact that a significant part of the sanctions of the articles of the Special Part of the Criminal Code was built in such a way that the court did not have the opportunity to choose any type of punishment other than imprisonment, including for minor or medium-gravity crimes. Let us consider this on the example of the original version of chapter 16 of the Criminal Code of the Russian Federation. Thus, in total, 42 sanctions were enshrined in this chapter, of which only imprisonment was provided for in 18 sanctions, including for minor or medium-gravity crimes - in 10 sanctions, which amounted to $23.8 \%$ of the total number of sanctions of this chapter. 15 sanctions of this chapter were virtually uncontested, as they provided such penalties as the restriction of liberty and arrest (which were not put into effect), as well as the deprivation of liberty as an alternative, which amounted to $35.7 \%$ of the total number of sanctions of the considered chapter. Thus, at the time of adoption of the Criminal Code, the share of unopposed sanctions with imprisonment (legally or actually) in chapter 16 of the Criminal Code of the Russian Federation was $78.6 \%$, of which $59.6 \%$ were sanctions for minor or medium-gravity crimes. The situation was similar for other chapters of the Criminal Code. This could not but affect the judicial practice. So, according to the Office of the Judicial Department under the Supreme Court of the Russian Federation, in 2003 a total of 773,920 people were convicted, of which 252,041 were sentenced to imprisonment with real serving (32.8\% of the total number of convicts), 426,048 - to suspended imprisonment $(55.7 \%)$. Thus, a total of $88.5 \%$ of convicts were sentenced to imprisonment in 2003. The year 2004 shows similar indicators. A total of 793,918 people were convicted, of which 257,284 (32.6\% of the total number of convicts) were sentenced to real imprisonment, $415,659(52.7 \%)$ were given a suspended sentence, respectively, the total proportion of convicts sentenced to imprisonment in 2004 was $85.3 \%$ [9].

"In 2003, implementing the tasks set by the President the State Duma makes a number of significant amendments to the Criminal Code of the Russian Federation, in particular, the institution of repeated crimes was excluded, the scope of alternative types of punishment was expanded, significantly reduced, and in some cases the responsibility for careless crimes was completely abolished, penalties for tax crimes were reduced" [7, p. 35]. Besides, within the framework of humanization (we note only the most significant points taking into account the topic of research) the possibilities of exemption from criminal liability were expanded due to the addition of Art. 75 and Art. 76 of the Criminal Code indicating moderate crimes, the maximum limits of deprivation of liberty for minors were revised, the scope of application of compulsory educational measures was increased, etc.

The announced course towards the liberalization of the criminal policy and the amendments made to the Criminal Code led to the fact that the practice of applying penalties began, albeit gradually and very slowly, to change. Thus, while the proportion of convictions to prison terms with real sentences has not changed and remained in the range of $33-35 \%$ between 2005 and 2007, the proportion of convictions with suspended sentences has gradually decreased from $55.5 \%$ in 2003 to $45.1 \%$ in 2007 [9]. Since 2008, the share of convicts both to imprisonment with real serving has decreased from $33.9 \%$ in 2008 to $29.4 \%$ in 2019 , and convicts sentenced to suspended imprisonment - from $38.8 \%$ in 2008 to $26.5 \%$ in 2019 [10]. The increased use of fines in practice is noteworthy. Thus, while in 2003 the proportion of persons who were fined as the main penalty was only $6.5 \%$, by 2007 it had risen to $12.9 \%$ [9]. However, between 2003 and 2007, there was no significant increase in the use of other types of punishment, including the fact that despite extensive changes in the Criminal Code in 2003, a significant number of sanctions remained unopposed, and in some of them the deprivation of liberty was an alternative only with a fine [11]. A new version of Art. 50 of the Criminal Code regulating corrective labor turned out to be quite unsuccessful. Now this type of punishment could be imposed only to persons without a primary employment, which significantly limited the possibility of using this punishment, as there were problems in determining the places for its execution.

Subsequently, the work on supplementing the sanctions contained in the articles of the Special Part of the Criminal Code with other penalties alternative to deprivation of liberty was continued. Besides, changes were made to the regulation of certain types of punishment, which led to an increase in the possibility of their use. For example, the procedure for the use of corrective labor was changed due to the reference to the possibility of imposing this type of punishment both to persons with and without primary employment in Art. 50 of the Criminal Code. The punishment in the form of 
restriction of freedom and compulsory labor received a new content. This led to their increased use in practice.

As a result, the number of convicts sentenced to other penalties not related to deprivation of liberty increased. For example, the share of convicts to compulsory labor increased from $5.3 \%$ in 2008 to $16.8 \%$ in 2019 , to corrective labor from $5.2 \%$ to $8.4 \%$, to restriction of freedom from $0.9 \%$ in 2010 to $3.4 \%$ in 2019 . The conviction to a fine as the primary punishment is also relatively stable - the proportion of persons sentenced to it ranges from $12.6 \%$ to $15.9 \%$ [9].

Although in recent years, unlike other punishments, there has been a steady decrease in the number of sentences with a fine, which on the one hand may be due to the wider use of other types of punishments, and on the other - to the difficulties in the execution of this punishment.

Large-scale changes of the Criminal Code of the Russian Federation, which were motivated by the need for "further liberalization of the criminal legislation", took place in March 2011. The main emphasis in the Law No. 26-FZ of 07.03.2011 [12] was on the exclusion of such lower limits as imprisonment, arrest and corrective labor from sanctions of articles of the Special Part of the Criminal Code. According to researchers, "the result of the adoption of this Law was the abolition of the lower limits of sanctions in the form of imprisonment under 68 articles of the Criminal Code, including some serious and especially serious crimes" [13, p. 37].

Adjustments were made to the procedure for abolishing conditional release and release on parole, according to which, unlike the previous version, the commission of the medium-gravity crimes by a convict now does not entail the automatic abolition of conditional sentence or parole, but is left at the discretion of the court.

Later, in December 2011, Art. 15 of the Criminal Code of the Russian Federation was set out in a new version, according to which the range of crimes classified as minor by increasing the upper limit of the maximum sentence of imprisonment to three years, as well as allowing courts to change the category of crime to a milder, but not more than one category. Art. 56 of the Criminal Code of the Russian Federation established restrictions on the appointment of imprisonment to persons who first committed a crime of minor gravity. The Criminal Code was supplemented by a new type of exemption from criminal liability - in cases of crimes in the field of economic activity (Art. 761 of the Criminal Code of the Russian Federation), as well as a new type of exemption from punishment - postponement of serving a sentence to drug addicts (Art. $82^{1}$ of the Criminal Code of the Russian Federation).

In addition to the above, the innovations aimed at humanizing the criminal law also include such as the return to administrative precedence, the addition of the Criminal Code with such a different criminal law measure as a court fine, and, accordingly, the inclusion of a new type of exemption from criminal liability - in connection with the appointment of a court fine (Art. $76^{2}$ of the Criminal Code of the Russian Federation), the credit for the term of serving a sentence with a person's detention in custody (Art. 72 of the Criminal Code of the Russian Federation) and some others.

Clearly, a number of changes in the criminal law should be recognized as positive. In particular, the expansion of the variability of sanctions, the reform of the criminal punishment system, which made it possible to use its potential in a larger volume, a more balanced approach to the implementation of criminal liability for minors, limiting the possibility of imposing deprivation of liberty on persons who first committed a crime of minor gravity and some others. But in general, a series of unsystematic changes in the criminal legislation led to a number of negative consequences, which were repeatedly addressed in the theory of the criminal law, and which almost completely offset the achievements of the modern legislator that were achieved at the first stages of the reform of the Criminal Code. Thus, in particular, summarizing the positions existing in the theory of the criminal law, A.I. Korobeev, among others, indicates the following problems:

“... - absence of a consistent normative and theoretical concept of the content and form of the criminal legal response to the crime, the relationship of punishment and other criminal legal measures;

- wide and even improper scope of judicial discretion in determining not only the measure of criminal punishment, but also the grounds for criminal liability;

- non-conformity of the declared goals of the criminal punishment with the real possibilities in their achievement, the inferiority of the system of penalties; the inconsistency of private and public legal principles of criminal law regulation, the unresolved issue of the criminal law status of the victim of the crime;

- inconsistency of provisions on the inevitability and appropriateness of criminal prosecution and criminal liability..." [14, p. 56].

In general, we evaluate the processes of humanization (liberalization) positively, and support the law enforcement officer in the chosen tactics of the widespread use of other forms of the criminal legal pressure. Statistics show that modern law enforcement practice has ceased to focus exclusively on punishment as the only possible and effective form of the criminal law pressure.

For example, according to the information of the Office of the Judicial Department at the Supreme Court of the Russian Federation, in 2020 a judicial act on the merits of the charge was issued against 721,422 persons, of which 530,965 were convicted. $25 \%$ of the persons whose cases reached the court were not convicted on various grounds, including 99,078 in connection with the settlement with the injured party; 56,976 people - with the imposition of a court fine; 7,256 people - with active repentance. 147,257 people were sentenced to probation, which amounted to $27.7 \%$, probation to other types of punishment - 10,320 people (1.9\%) [15].

However, there is some concern about the use of the criminal justice measures in relation to offences classified by the legislator as grave and especially grave crimes. So, in 2020, 25,945 people were convicted of especially grave crimes. Of these, 24,676 people were 
sentenced to imprisonment. 4,952 persons were sentenced to more than 10 years in prison with a real sentence, which is $20 \%$ of the total number of convicts for especially grave crimes. At the same time, 1,000 people were sentenced to probation. 115,671 people were convicted of grave crimes. Of these, from five to ten years in prison with a real sentence $-3,558$ people, which is $3 \%$ of the total number of convicts for grave crimes. 58,812 people, or $50.8 \%$ were sentenced to probation.

In second place after a suspended sentence are sentences with imprisonment for a term of three to five years $-17,009$, or $14.7 \%$. Taking into account the above, it can be concluded that only $20 \%$ of convicts for especially grave crimes are sentenced, corresponding to the category declared in the Criminal Code with regard to grave crimes - here the proportion is even less $-3 \%$. At the same time, more than half of the perpetrators have a conditional sentence. 1,407 persons who committed grave crimes were exempted from criminal liability in connection with the imposition of a court fine [15]. This is an example of only one year, but a similar situation was observed in previous years. In other words, we see that despite the fact that the legislator in Art. 15 defines quite high limits of punishment for committing grave and especially grave crimes, real judicial practice goes along the path of sentencing corresponding to a different, milder category. Such a widespread use of probation for committing grave crimes is also doubtful, since it imposes minimal restrictions on the convicted person, even in comparison with milder types of punishment.

And here there are questions about how such judicial practice can ensure the security of the person, society and the state? Can the confidence of citizens in the law enforcement and judicial systems of the Russian Federation be increased with such indicators, as indicated in the National Security Strategy? How humane is the approach to perpetrators of grave and especially grave crimes consistent with the principle of justice?

\section{Conclusion}

In summary, there is a view in the theory of the criminal law that "the criminal law, being punitive in essence, cannot and should not be treated to a person who committed the crime as a partner: it always requires an answer from this person and, as a general rule, punishes him for what he did" [16, p. 298]. However, we believe that in each case it should be a question of choosing the most optimal forms and means of responding to criminal behavior, the enforcer should proceed from the principle of saving criminal repression, the reaction to the crime committed should be flexible, reasonable and expedient, taking into account the circumstances of a particular case and the characteristics of a person who committed the act prohibited by the Criminal Code. Our position on this issue is confirmed by judicial statistics, since, despite the dominance of criminalization processes, the number of convicts in Russia is declining, and the use of other criminal legal measures alternative to punishment is expanding.

However, when choosing a specific measure, it should not be forgotten that it should be proportionate to the nature and extent of the social danger of the offence (i.e. fair) and inescapable. It is impossible either in legislative or law enforcement activities to ignore those guiding ideas that are defined in Art. 3-7 of the Criminal Code of the Russian Federation, since they are developed in the process of historical development of society and are important for ensuring the national security. Given the above, we believe that the situation that has developed in terms of the criminality of grave and especially grave crimes can lead to a feeling of impunity in the public mind, violation of the principles of justice and humanism (after all, humanism presupposes primarily the security of a person, a lawabiding person).

Clearly, one of the reasons for the situation with regard to the choice by the courts of measures to respond to the commission of these categories of crimes is the imperfection of the current system of criminal penalties. In fact, the modern legislator can offer nothing to the law enforcement officer as an alternative to imprisonment for crimes of these categories.

Of the 13 penalties, only fines and compulsory labor (we do not talk about the death penalty and life imprisonment, since the first is not used in Russia, and the second is rarely used in practice and is included in a limited number of sanctions on the articles of the Special Part of the Criminal Code) are alternative to imprisonment in the sanctions of articles of the Special Part of the Criminal Code for grave and especially grave crimes.

However, the possibility of using compulsory labor is limited, firstly, by the fact that such works can be assigned a maximum for a grave crime, and secondly, the crime must be committed for the first time. As for the fine, it is also included in some sanctions for especially grave crimes, but with the place it occupies today in the "ladder" of punishments, this seems contrary to logic, since the mildest punishment is almost alternative to the strictest.

Thus, the modern Criminal Code today includes a fairly extensive system of criminal legal measures. However, in this system we do not see logical completeness, slimness and sequence.

Therefore, we consider it necessary to invite the legislator not to continue to make absurd changes to the criminal law, related to the exclusion of lower limits of punishment in the sanctions of articles of the Special Part of the Criminal Code, allowing the possibility of changing the category of crime, rash reform of the criminal punishment system, and focus on the establishment of a fully-fledged system of criminal justice measures with a clear understanding that each of them is separate, and the system as a whole must effectively protect the interests of the individual, society and the state, as well as comply with the principles defined in Art. 3-7 of the Criminal Code of the Russian Federation, including the principle of humanism. 


\section{Acknowledgments}

The paper was prepared with the support of the Russian Foundation for Basic Research (RFBR), project No. 20011-00141 A "Criminal legal impact as a state reaction to crimes and criminal practice and its role in ensuring the national security of Russia".

\section{References}

1. Decree of the President of the Russian Federation No. 683 "On the National Security Strategy of the Russian Federation" dated 31.12.2015; Legislative Assembly of the Russian Federation. No. 1 (Part II). Art. 212 (2016)

2. V.K. Duyunov, Reform of criminal legislation should be justified, Bulletin of Samara Humanitarian Academy. Series: Law, 1(11), 12-18 (2012)

3. A.I. Korobeev, Criminal law policy of modern Russia: problems of penalization and depenalization, Law, 8, 46-59 (2015)

4. S.M. Inshakov, V.A. Kazakova, Methodological approaches to the criminality of crimes from the perspective of modern criminal policy, Criminal law, 1, 84-92 (2016)

5. Federal Law No. 162-FZ "On Amendments and Additions to the Criminal Code of the Russian Federation" dated 08.12.2003; Collection of Legislation of the Russian Federation. No. 50. Art. 4848 (2003)

6. S. Markuntsov, Characteristics of changes in the criminal legislation of Russia and China, BRICS LAW JOURNAL, 5(4), 90-113 (2018)

7. V.F. Tsepelev, Current state of Russian criminal law and its influence on the development and implementation of the criminal policy, Russian Investigator, 7, 43-46 (2019)

8. K.A. Volkov, Criminal policy and judicial practice, Russian judge, 2, 34-38 (2019)

9. Main statistical indicators of the state of criminal record in Russia for 2003-2007. Retrieved from: http://www.cdep.ru/index.php?id=79\&item=2074. Date of address: 04.05.2021.

10. Main statistical indicators of the state of criminal record in Russia for 2008-2019. Retrieved from: http://www.cdep.ru/index.php?id=79\&item=2074. Date of address: 05.05.2021.

11. I.A. Podroykina, Fine as a type of punishment in modern criminal law: candidate dissertation (Rostov-on-Don, 2004) 220 p.

12. Federal Law No. 26-FZ "On Amendments to the Criminal Code of the Russian Federation" dated 07.03.2011. Collection of Legislation of the Russian Federation. No. 11. Art. 1495 (2011)

13. P.V. Teplyashin, D.S. Vasiliev, Effectiveness of humanism in crime prevention, Russian investigator, 14, 36-39 (2013)

14. A.I. Korobeev, Criminal law policy of modern Russia: problems of penalization and depenalization, Law, 8, 46-59 (2015)

15. Summarized statistics on the state of criminal record in Russia for 2020. Retrieved from: http://www.cdep.ru/index.php?id=79\&item=5669. Date of address: 05.05.2021.

16. A.I. Rarog, Relationship of the interests of the individual and the state in criminal law of the Russian Federation, All-Russian criminological journal, 14(2), 298-304 (2020) 